\title{
Impacto Redistributivo dos Gastos Sociais nas Regiões Metropolitanas no Nordeste do Brasil, em 2004
}

\section{Redistributive impact of social spending in the metropolitan regions in northeast of Brazil, in 2004}

Lucilena F. Castanheira Corrêa* João Policarpo R. Lima**

Resumo: O objetivo deste trabalho é analisar a magnitude do impacto dos gastos sociais, representados pelas variáveis: pensão, seguro desemprego, transferência de renda de programas sociais e merenda escolar, na renda das famílias situadas nas Regiões Metropolitanas de Fortaleza, Recife, Salvador, no ano de 2004, visando a contribuir para a avaliação da efetividade dos referidos gastos para a redução dos problemas sociais existentes. Para isso, foram utilizados três índices: Gini, concentração e progressividade, construídos através dos microdados da Pesquisa de Amostragem Domiciliar - PNAD, IBGE.

Palavras-chave: Desigualdade de renda. Transferência de renda. Pobreza.

Abstract: The purpose of this work is to analyze the magnitude of the impact of social spending, represented by variables such as pensions, unemployment insurance, transfer of income from social programs and school lunch, on familiar income in the metropolitan regions of Fortaleza, Recife and Salvador, in the year 2004, with the goal of contributing to evaluate the effectiveness of those expenses in reducing the social unevenness. In this sense, three indexes were used: Gini, concentration and progressivity, built from the microdata of the household survey sampling - PNAD, IBGE.

Keywords: Inequality of income. Transfer of income. Poverty.

JEL Classification: I38.

\footnotetext{
* Doutoranda em Economia pelo Programa de Pós-Graduação em Economia (Pimes) da Universidade Federal de Pernambuco (UFPE). E-mail: lucilena_castanheira@hotmail.com

** PhD. em Economia pela University College London. Professor-Associado da Universidade Federal de Pernambuco (UFPE) e pesquisador do CNPq. E-mail: jprlima@ufpe.br
} 


\section{Introdução}

A desigualdade de renda e a pobreza no Brasil estão entre os maiores desafios a serem enfrentados na área social. Sobre isso, podem-se ressaltar estudos que concluem que o Brasil levaria mais de 25 anos para reduzir a taxa da população de pessoas pobres para valores inferiores a $15 \%$, se for mantido um crescimento per capita de $3 \%$ aa, Barros, Henriques e Mendonça (2000). ' É verdade que, nos anos mais recentes, parece ter havido alguma melhora na distribuição de renda, tendo Barros et al. (2007), constatado que, entre os anos de 2001 e 2005, a queda do grau de desigualdade de renda no Brasil se deu de forma muito acelerada e contínua. O estudo em questão verifica que a concentração de renda medida pelo Coeficiente de Gini teve uma redução da ordem de 5\%, e que esta redução está relacionada com duas fontes de renda: uma através do aumento da renda não derivada do trabalho e a segunda da renda do trabalho, sendo esta última a responsável por um terço na queda do grau de desigualdade. Mas, mesmo assim, a desigualdade de renda no Brasil ainda é muito grande, estimando-se que para alcançar a média mundial o país levará 18 anos, se for mantido o mesmo ritmo na redução do grau de desigualdade de renda.

Fica evidente então que o Governo está diante de um grande desafio social que somente poderá ser resolvido com a velocidade necessária com o uso de políticas sociais que levem a um aumento na renda das famílias mais pobres e a uma distribuição mais equitativa da renda.

O objetivo principal das políticas sociais elaboradas e executadas pelo Governo é, então, acarretar uma melhoria na distribuição de renda, principalmente das famílias mais pobres. Porém, essas políticas só conseguirão atingir tal objetivo se, tanto a elaboração como a execução, forem focalizadas e se deem de forma eficiente. Políticas sociais são realizadas mediante as transferências diretas de renda e através de produção de bens e serviços sociais.

Sendo assim, estudos direcionados aos impactos redistributivos dos programas sociais passam a ser um importante instrumento no acompanhamento e na eficácia das políticas sociais. Sobre isso, parece

1 Segundo Barros et al. (2000), em 1999, o Brasil possuía uma população de 53 milhões de pessoas pobres e 22 milhões de indigentes, sendo que 55\% com uma renda média abaixo do valor da linha de pobreza e, destes, $60 \%$ situavam-se abaixo da linha de indigência. Estes mesmos autores utilizam-se do coeficiente de Gini para fazer uma comparação da desigualdade de renda entre o Brasil e o mundo, este representado por 92 países, e concluem que o país ficou em antepenúltimo lugar, ou seja, somente à frente de países como o Malavi e a África do Sul, sendo que quando se refere ao grau de desigualdade em razão da renda dos $10 \%$ mais ricos e dos $40 \%$ mais pobres, o Brasil ocupa a última posição. 
relevante, antes de examinar os dados, uma breve revisão bibliográfica sobre o tema.

Irarrázavel (1994) analisa o impacto resdistributivo como uma forma de mensurar os efeitos diretos das políticas ou dos programas sociais na renda das famílias. O estudo do autor vem contribuir no sentido de mostrar a existência de medidas com objetivo de tornar os gastos sociais mais igualitários, através do índice de progressividade, podendo ser analisado se os mesmos estão sendo progressivos, ou seja, se eles estão sendo focados em maior parte para as famílias mais carentes.

Soares (1999) desenvolveu um estudo sobre o impacto redistributivo dos gastos sociais para a Região Metropolitana de São Paulo. Utilizando-se de dados da Pesquisa de Condições de Vida - PCV para São Paulo, do ano de 1994, e da metodologia proposta por Irarrázel (1994), concluiu que tanto as transferências quanto os serviços são importantes para a redução da concentração de renda, e que os serviços têm maior importância. Em seu estudo, Soares (1999) destacou também ser importante que os estudos sejam feitos em caráter regional, haja vista as grandes disparidades existentes entre as regiões brasileiras.

Sendo assim, no Brasil a ação pública também tem de levar em consideração as desigualdades inter-regionais. Enquanto de um lado temos regiões mais ricas, de outro temos regiões em desenvolvimento ou mesmo pobres. Este é outro fator que merece ser destacado como variável muito importante para o estudo do impacto redistributivo dos gastos sociais, ou seja, constatar se realmente os subsídios e principalmente os programas estão sendo focados nas regiões mais carentes.

Mostajo (2000) alega que os estudos de impacto distributivo mostram que uma parte importante dos recursos sociais é destinada às populações mais carentes, como forma de serviços ou subsídios, e que quando se combina eficiência e equidade esse impacto é refletido no grau de incidência da ação pública na renda das famílias mais pobres.

Sendo assim, o objeto deste trabalho centra-se na análise do impacto dos programas sociais de transferência de renda para as Regiões Metropolitanas do Nordeste, ou seja, procura aferir se as políticas sociais estão realmente direcionadas à região com maior desigualdade de renda. Além disso, busca evidências para avaliar se os gastos através de transferência de renda efetuados no Nordeste estão apresentando a efetividade necessária para a redução dos problemas sociais existentes. O estudo utilizará microdados da Pesquisa Nacional por Amostragem de Domicílio - PNAD do ano de 2004 e, assim, ordenará as famílias com renda per capita de acordo com os estratos socioeconômicos.

A partir da estratificação do nível de renda per capita das famílias, foi efetuada análise utilizando como instrumento índices de desigualdade de 
renda, o índice de concentração e o índice de progressividade em dois momentos: o primeiro, antes da introdução dos gastos sociais na renda inicial e, no segundo momento, após a introdução dos gastos sociais, com o objetivo de observar a proporção em que a mesma foi alterada.

Parte-se do entendimento de que os recursos destinados às Políticas Sociais por parte do governo devem ter sua focalização eficiente, para que o objetivo principal, que é a redução da pobreza, possa ser concretizado.

Tem-se ainda como premissa a visão expressa por Bravo e Contreras (2004, p. 106) segundo a qual "Medir la distribución del ingresso sin considerar el gasto social no es correcto, pues sobreestima la desigualdad".

Desta forma os objetivos específicos do presente estudo são: i) utilizar o coeficiente de Gini para medir a concentração de renda antes da introdução dos programas de transferência de renda; ii) medir a proporção das variáveis selecionadas - pensão, seguro desemprego, transferência de renda de programas sociais e merenda escolar - que constituem os gastos sociais que chegam à população-alvo, ou seja, à população carente e excluída, tanto social quanto economicamente; iii) analisar a variação na distribuição de renda a partir da introdução dos gastos sociais; iv) avaliar a incidência dos gastos sociais por faixa de renda.

\section{Metodologia}

O objeto central do estudo sobre incidência dos programas sociais de transferência de renda é mostrar como estes gastos interferem, na distribuição de renda da população estudada, com vistas a observar se estão melhorando as condições de vida das famílias de baixa renda.

A Pesquisa Nacional por Amostra de Domicilios - PNAD (Suplemento Complementar em Transferências de Renda de Programas Sociais e Educação) - 2004 foi utilizada como instrumento para se obter os dados numéricos que permitiram analisar o grau diferenciado da incidência desses gastos. A escolha da pesquisa mencionada está atrelada ao seu conteúdo, ou seja, a mesma é composta por algumas variáveis que estão sendo estudadas no presente trabalho. Vale salientar que os dados foram tratados em nível familiar, quando da utilização dos microdados da pesquisa em referência. Note-se que, embora, o mesmo instituto possua uma pesquisa mais abrangente, ou seja, o Censo, para o ano de 2000, a PNAD de 2004 apresenta em sua metodologia novas variáveis que são destacadas neste trabalho, as quais o Censo de 2000 ainda não possuía.

O que se quer dizer é que a PNAD do ano de 2004 tem uma novidade em sua amostra suplementar no que se refere à transferência de 
renda direta ou ao recebimento de dinheiro de programas sociais por algum membro do domicílio ou da família, efetuadas pelo governo no mês de referência da pesquisa (setembro de 2004). Aqui encontram-se, entre outros: Auxílio-Gás; Bolsa-Família; Cartão Alimentação do Programa Fome Zero; Bolsa-Alimentação; Benefício Assistência de Prestação Continuada - BPC - LOAS; Bolsa-Escola; Programa de Erradicação do Trabalho Infantil - PETI - ou outras eventuais fontes de algum outro Programa Social do Governo Federal, Estadual ou Municipal

Embora o questionário do PNAD traga avanços na captação de dados de transferência de renda de programas sociais, a sua aplicação mostrou-se limitada. Tanto que o IBGE, devido a problemas nas respostas das variáveis que compõem este programa, sugere que os mesmos não sejam tratados de forma desagregada. Isso porque algumas famílias não souberam especificar exatamente o programa em que estavam inseridas, ou ainda, no caso de terem recebido renda de mais de um programa, as mesmas não souberam definir os valores exatos de cada um deles em que eram beneficiadas.

Levando-se em conta tais limitações, as informações foram agrupadas em variáveis, da seguinte forma:

i) Renda per capita domiciliar: é a renda de todas as fontes dividida pelo número de componentes da família (excluindo pensionistas, empregados domésticos e parentes, e crianças com menos de 10 anos de idade); ii) Às transferências de renda de programas sociais - TRPS, foram atribuídos, para cada programa, valores coletados através do site do Ministério do Desenvolvimento Social e Combate à Fome (MDS).

Para esse estudo, primeiramente as famílias são ordenadas de forma crescente de acordo com suas rendas. Isso, em vista do objetivo deste, que é averiguar se essas famílias estão sendo as principais beneficiadas, sob a óptica dos objetivos centrais da política social em pauta.

Vale ressaltar que os estudos de impacto redistributivo dos gastos sociais utilizam três definições para renda, conforme Soares (1999): i) a primeira refere-se à renda própria ou autônoma, ou seja, a renda proveniente do próprio trabalho, dos aluguéis, das pensões alimentícias etc.; ii) a segunda definição de renda é a monetária, que é o resultado da soma da renda própria mais as transferências em dinheiro de programas sociais efetuados pelo governo; iii) a terceira definição é o conceito de renda total, que é o resultado da soma da renda monetária mais os subsídios sociais em forma de bens e serviços, como alimentação escolar. A metodologia para valorar a produção de bens e serviços sociais se define em valor de gasto unitário, a variável que constituirá o quesito serviços sociais será a Educação e a mesma será construída como definido a seguir. Merenda escolar: o valor foi obtido no site do Ministério 
de Educação - MEC -, abrangendo nesta variável, alunos da pré-escola e do Ensino Fundamental. Note-se que o valor imputado elevou-se em $15,38 \%$, passando de $R \$ 0,13$ para $R \$ 0,15$ por aluno/dia, conforme divulgado pelo Fundo Nacional de Desenvolvimento da Educação FNDE. ${ }^{2}$ Calculou-se o benefício mensal de $\mathrm{R} \$ 4,00$, em agosto de $2004 .{ }^{3}$

Diante dessa classificação, a análise realizada considerou o efeito dos gastos sociais relativos a transferências mais a valoração de outro componente social - a merenda escolar - sobre a renda própria, dada como renda inicial.

A descrição matemática de cada variável é demonstrada a seguir:

$$
Y_{t}=Y_{m}+M_{\tau}
$$

onde:

$Y_{t}=$ renda total

A renda monetária é definida da seguinte forma:

$\mathrm{Y}_{m}=\mathrm{RP}+\mathrm{TLT}+\mathrm{TRPS}$,

sendo que:

$\mathrm{Y}_{m}=$ renda monetária, a renda própria da família, proveniente de todas as fontes, inclusive a aposentadoria + pensões e seguro desemprego + TLT (Transferências Ligadas ao Trabalho) + TRPS (Transferências de Renda dos Programas Sociais)

$\mathrm{M}_{\tau}=$ merenda escolar

As famílias foram ordenadas de acordo com sua renda própria per capita sem as transferências de renda de programas sociais -TRPS - e classificadas do menor ao maior nível de renda, divididas por decis (10\%) e assim perfazendo todos os níveis com o mesmo peso. Desse modo, os primeiros decís correspondem às famílias de menor renda e os últimos decís correspondem às famílias de maior renda. Este ordenamento levará em consideração o conceito atribuído por Irarrázaveal (1994) segundo o qual a renda própria per capita da família pode ser obtida através da renda própria total da família dividida pelo número de pessoas que compõem a família.

Complementando a parte metodológica deste trabalho, recorremos a Vélez (1997), cujo estudo enfoca os gastos sociais na Colômbia - educação, saúde e seguridade social - utiliza como medida para o

2 Disponível em: <http://www.fnde.gov.br/home/index.jsp?arquivo=/alimentacao_escolar/ alimentacao_esc.html\#dadosesta>. Acesso em: 1 jul. 2006.

3

$\mathrm{O}$ valor $0,15 \times 26$ (dias úteis) $\approx \mathrm{R} \$ 4,00$ 
impacto redistributivo dos gastos sociais os indicadores de desigualdade, concentração e de progressividade, a saber:

- O índice de Gini $(G)$ - A partir da variável "renda própria per capita familiar", classificada de forma crescente e acumulada, foram construídos os níveis de renda das famílias, a partir de agora chamados de decís (1 a 10), ou seja, os primeiros decis representam as famílias de baixa renda e os últimos caracterizam as famílias que possuem as maiores rendas per capita. Logo, a distribuição de renda é identificada em cada decil (do primeiro ao último), bem como sua representação gráfica se dá através da Curva de Lorenz - $L(p)$. Ela representa a porcentagem da população ( $p \%$ ) que detém a maior parcela da renda distribuída no país. O gráfico de representação da riqueza, a seguir, demonstra que quanto maior for a área de concentração, maior será a concentração de renda e, quanto menor for esta área, a distribuição de renda do país mostrar-se-á mais igualitária. Desse modo, a Curva de Lorenz é representada pela curva abaixo da diagonal que indica distribuição igualitária e, quanto mais próximo de 1 , a relação entre as duas áreas reflete a maior concentração. O coeficiente de Gini corresponde à área entre a Curva de Lorenz e a diagonal de distribuição igualitária, ou seja,

$$
G=1+\frac{1}{N}-\frac{2}{\mu N^{2}} \sum Y_{i}(N+1-i)
$$

Onde:

$N \rightarrow$ número de pessoas ou nível de renda;

$i \rightarrow$ indica o número da ordem da pessoa no nível de renda, ou seja, decil:

$i=1, \ldots, 10$.

$\mu \rightarrow$ é a renda média da economia;

$Y \rightarrow$ renda da pessoa no nível de $i$, ou seja, $Y_{1}$ representa a renda no primeiro decil, o mais pobre, e $Y_{10}$, a renda no decil mais rico. 


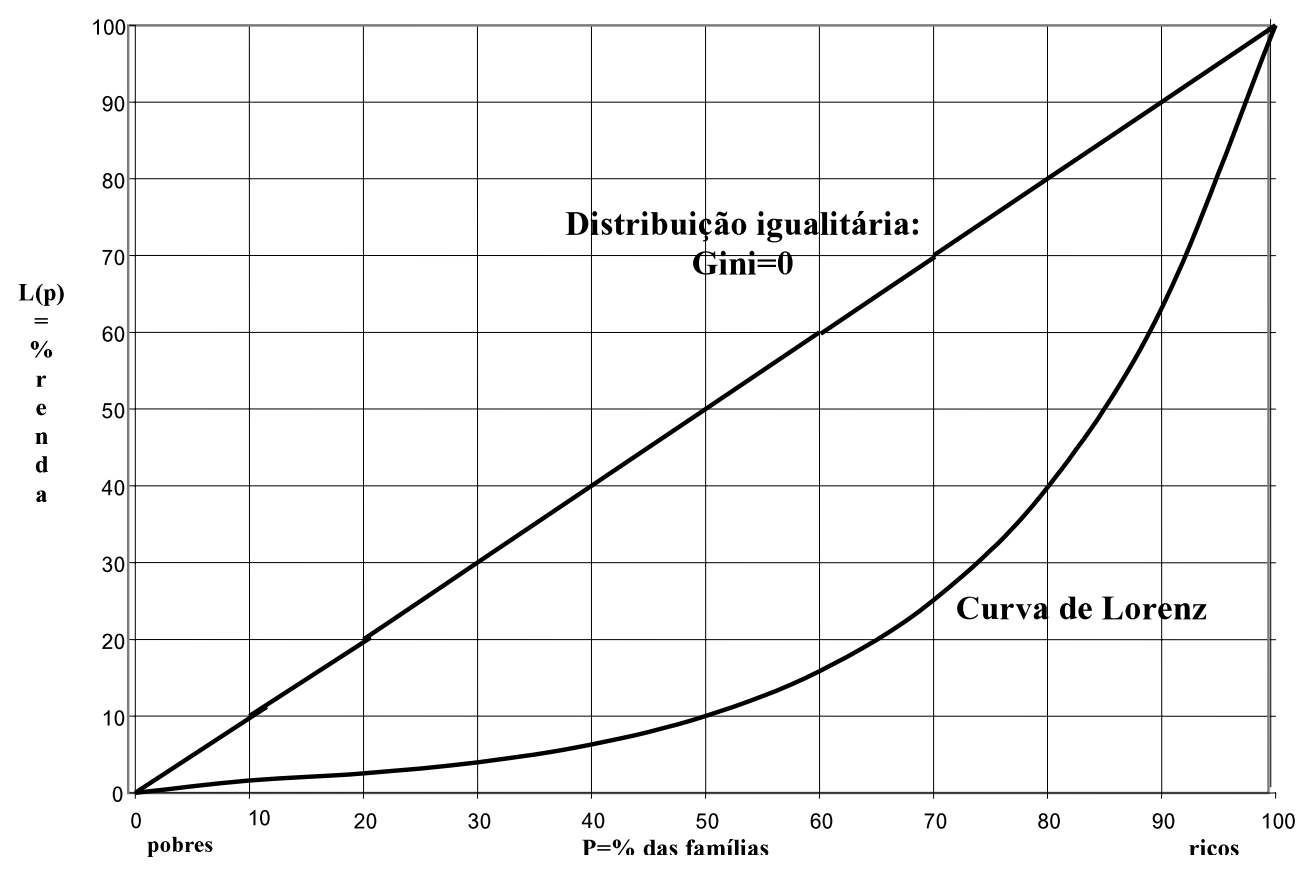

Figura 1 - Curva de Lorenz

Fonte: Elaborada pelos autores.

Vale notar que adotou-se como referência o estudo de Vélez (1997), cujos indicadores adotados para medir os impactos redistributivos dos gastos sociais através da transferência de renda de programas sociais fundamentam a metodologia adotada neste trabalho. Segundo o autor,

Para medir a progressividade relativa de um subsídio em relação à distribuição de renda, é utilizado o coeficiente de progressividade, Ps, que é igual à diferença entre o coeficiente de concentração dos subsídios, Cs, e o coeficiente de Gini, G, na distribuição de renda. (VÉLEZ, 1997, p. 50, tradução nossa).

Assim, em seu estudo, Vélez calcula a diferença entre índice de Gini antes da introdução da transferência de renda dos programas sociais e após a introdução da transferência de renda de programas sociais. Pressupõe-se que a maior progressividade, indica que a maior parte dos gastos sociais está sendo destinada à população de nível de renda mais baixo. $\mathrm{O}$ autor discorre sobre a necessidade de medir os efeitos na distribuição dos gastos sociais sobre a renda, comparando o antes da introdução dos gastos sociais e seu comportamento após a inclusão das transferências de renda dos programas sociais por parte do Estado, ou seja, se a focalização desses gastos sociais está sendo concentrada na parcela da população para que se destina, ou seja, a mais carente.

Assim, $\Delta G=G f-G$ 
Onde:

$G \rightarrow$ Coeficiente de Gini antes da introdução da transferência de renda de programas sociais;

$\mathrm{G} f \rightarrow$ Coeficiente de Gini depois da inclusão da transferência de renda de programas sociais.

- O índice de Concentração - demonstra a porcentagem dos subsídios - transferência de renda de programas sociais - referentes aos gastos sociais que são destinados para p\% (percentual da população dos mais pobres). É baseado no índice de Gini, cujo resultado é obtido através do dobro da área entre a curva de destino dos recursos e a diagonal que é representada por uma reta de $45^{\circ}$ graus. A curva de destino dos recursos é obtida a partir da ordenação da renda dos indivíduos antes beneficiados pela transferência de renda dos programas sociais. $\mathrm{O}$ indicador pode variar de -1 a 1. Quanto mais negativo, mais progressivo foi o gasto, sendo que um indicador zero indica a neutralidade dos gastos. A representação do Coeficiente de Concentração demonstrado através da Curva de Concentração (C) é dada da seguinte maneira, conforme mencionado por DIAZ (2003, p. 10).

$$
C=1-2 \int_{0}^{1} C_{(s)} d s, \text { sendo }-1 \leq C_{s} \leq 1
$$

E a curva de Concentração pode estar situada tanto acima como abaixo da linha igualitária, diferenciando-se da Curva de Lorenz. 


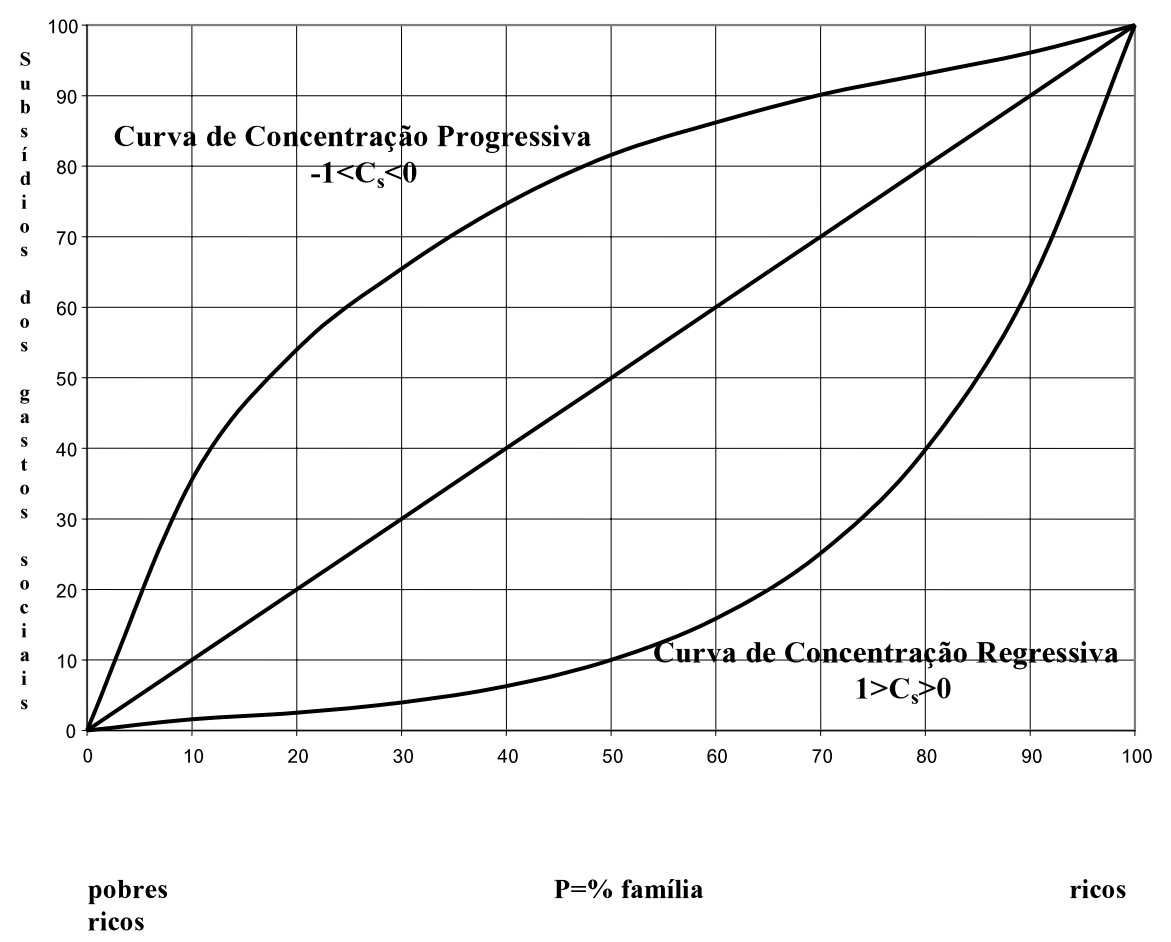

Figura 2 - Curva de Concentração e Coeficiente de Concentração Fonte: Elaborada pelos autores.

Deve-se ressaltar que $C$ tenderá a ser igual a zero quando $C_{(s)}$ estiver mais próxima da diagonal e será positivo quando $C_{(s)}$ situar-se acima da diagonal. Onde $C_{(s)}$ resulta na proporção acumulativa das famílias, ordenada pela sua renda per capita sem transferências de renda dos programas sociais, iniciando-se pelos indivíduos que se encontram em situação mais desfavorável nos primeiros decís e os mais ricos nos últimos decís. Se a variável assumir valores maiores, quanto pior for o nível de renda do indivíduo e a curva de concentração $C_{(s)}$ situar-se acima da diagonal constata-se a existência de desigualdades na renda e o subsídio - transferência de renda de programas sociais - resultantes dos gastos sociais estão focados para as populações situadas nos níveis mais baixos, ou seja, os mais pobres. Caso contrário, se os gastos sociais estiverem tendo como beneficiários as famílias com renda maior, a curva se situará abaixo da reta de $45^{\circ}$ graus. Neste caso, os programas sociais estarão sendo destinados às famílias com renda maior, evidenciando a deficiência na focalização dos gastos sociais.

\section{Análise dos Resultados}

Esta seção é uma tentativa de análise dos impactos dos gastos sociais do governo na renda das famílias mais pobres. Evidentemente, não se propõe, aqui, avaliar a totalidade dos programas sociais do governo. 
Pretende-se, na realidade, trabalhar com as variáveis: pensões, seguro desemprego, transferência de renda de programas sociais e merenda escolar.

Com base em informações contidas nos microdados do Instituto Brasileiro de Geografia e Estatística - IBGE - do ano de 2004, buscouse construir informações numéricas organizadas através de tabelas, utilizando-se como ferramenta o Microsoft Excel, que traduzissem resultados visíveis, embora permeados por algumas limitações metodológicas, entre elas a necessidade de restringir o número de variáveis que constituem os gastos sociais.

Antes de analisar os resultados aqui obtidos, vale salientar que os dados gerais do Instituto Brasileiro de Geografia e Estatística - IBGE sobre a variação relativa de famílias na linha de pobreza nas regiões metropolitanas do nordeste do Brasil, entre 2001 e 2004. ${ }^{4}$ Com base nesses dados, verificou-se que a Região Metropolitana do Recife apresentou uma elevação no número de famílias na linha de pobreza de aproximadamente $7,37 \%$, Fortaleza teve aumento de 7,27\%, porém, em Salvador, constatou-se uma trajetória oposta, ou seja, uma redução no número de famílias abaixo da linha de pobreza da ordem de 5,23\%.

Dito isso, faz-se em seguida, uma análise da distribuição e do impacto distributivo dos componentes do gasto social na renda das famílias da Região Metropolitana do Nordeste.

\subsection{Distribuição do Gasto Social nas Regiões Metropolitanas}

Conforme esclarecido anteriormente, neste estudo, os decis foram ordenados de modo que os grupos situados nos extremos inferiores são representados pela população mais carente e os colocados nos extremos superiores indicam o grupo de famílias mais ricas. As variáveis que foram analisadas como objetos deste trabalho são: pensões, seguro desemprego, transferência de programas sociais e merenda escolar, extraídas dos microdados do IBGE do ano de 2004, bem como sua distribuição através do coeficiente de concentração, podendo ser verificada na Tabela 1. 
Tabela 1 - Brasil - Coeficiente de concentração dos gastos sociais para as

Regiões Metropolitanas selecionadas, 2004.

\begin{tabular}{llllll}
\hline $\begin{array}{l}\text { Regiões } \\
\text { metropolitanas }\end{array}$ & TLT & TRPS & $\begin{array}{l}\text { Transferências } \\
\text { de renda }\end{array}$ & $\begin{array}{l}\text { Merenda } \\
\text { escolar }\end{array}$ & $\begin{array}{l}\text { Gasto } \\
\text { social }\end{array}$ \\
\hline Fortaleza & 0,5459 & $-0,0798$ & 0,4904 & $-0,1490$ & 0,4622 \\
Recife & 0,4634 & $-0,0531$ & 0,4059 & $-0,1576$ & 0,2150 \\
Salvador & 0,4236 & $-0,1117$ & 0,3981 & $-0,1624$ & 0,3628 \\
\hline
\end{tabular}

Fonte: Elaborada pelos autores com base em dados do Instituto Brasileiro de Geografia e Estatística (IBGE), PNAD (2004).

TLT $=$ pensão + seguro desemprego.

TRPS $=$ transferência de renda de programas sociais.

Transferências de Renda $=$ TLT + TRPS.

Gastos Sociais $=$ TLT + TRPS + Merenda Escolar.

$\mathrm{Na}$ Região Metropolitana de Fortaleza (RMF), o quesito - transferência de renda ligado ao trabalho, TLT - teve um perfil regressivo, ou seja, as famílias situadas nos níveis inferiores foram menos beneficiadas por este programa. Observa-se, que esta variável deve ser a responsável pela maior heterogeneidade na distribuição final da variável transferência de renda entre os decis. Constata-se, através do coeficiente de concentração, que houve "progressividade", mesmo que de menor grau nas variáveis TRPS e merenda escolar, embora o impacto positivo verificado sob a renda das famílias tenha sido de pequena magnitude.

A análise dos dados para a Região Metropolitana do Recife (RMR), demonstrou um desempenho muito parecido com aquele constatado na Região Metropolitana de Fortaleza (RMF).

A Região Metropolitana do Recife (RMR) apresentou a menor progressividade no coeficiente de concentração, no quesito transferência de renda de programas sociais - TRPS -, significando que esse programa ainda precisa ser mais bem focalizado nesta região.

O contraponto dessa análise pode ser verificado quando se analisa a distribuição do gasto social por decil de renda na Região Metropolitana do Recife (RMR), conforme tabela A.2 do Apêndice, e constata-se que $84,97 \%$ do total referente à variável transferência de programas sociais (TRPS) ficou centrado nos dois primeiros decis, embora a mesma apresenta um desempenho muito próximo da neutralidade quando se analisa o coeficiente de concentração dos gastos sociais dessa mesma região. Todavia, esta transferência de renda proveniente de programas sociais significa uma participação positiva na renda própria dessas famílias, uma vez que ela consegue melhorar o bem-estar das mesmas, o que indica a necessidade de uma melhor distribuição dessa variável entre as famílias dos níveis inferiores de renda. 
Quanto ao desempenho da Região Metropolitana de Salvador (RMS), no entanto, nos quesitos transferência de renda de programas sociais e merenda escolar, observa-se que o objetivo-alvo, constituído pela melhoria de renda real das famílias mais carentes, foi atingido em maior proporção, sendo esta região a que apresentou maior média em progressividade na concentração desses programas, entre as regiões do Nordeste.

Nesta região metropolitana (RMS), em relação à distribuição do gasto social por decil de renda, constata-se uma maior distribuição entre as variáveis estudadas em proporção à renda própria das famílias, conforme Tabela A.4 do Apêndice.

Em relação à transferência de renda dos programas sociais, a Região Metropolitana do Recife (RMR) foi a que apresentou a menor progressividade na distribuição das transferências provenientes dos programas sociais entre as famílias com níveis mais baixos, ficando evidenciado, através do coeficiente de concentração $(-0,0531)$. Todavia, essa variável teve uma importância significativa na renda própria per capita das famílias, representando $1,37 \%$ da renda própria per capita, conforme demonstrado na Tabela A.2 do Apêndice.

A merenda escolar apresentou a maior proporção na participação da renda própria das famílias da Região Metropolitana de Fortaleza (RMF), com percentual de 0,63\%, em comparação com a Região Metropolitana de Recife e Salvador, conforme Tabela A.3 do Apêndice.

No momento em que se soma a variável TRPS mais a merenda escolar, dá-se a chamada transferência de renda do governo para as famílias e a RMR foi novamente a mais beneficiada neste quesito, ou seja, o produto dessa soma representou 8,91\% da renda própria (Tabela A.2).

As pensões e o seguro desemprego são representados pela variável TLT - transferências ligadas ao trabalho formal, ou seja, o cidadão tem de contribuir através das contribuições sociais (trabalho com carteira registrada ou formal) para poder ter acesso a essas transferências de renda. Mais uma vez as famílias da RMR foram as mais beneficiadas por essas transferências, representando 7,54\% da renda própria per capita das famílias, conforme demonstrado na Tabela A.2 do Apêndice.

$\mathrm{O}$ que se constatou foi que as transferências ligadas ao trabalho (TLT) foram as que apresentaram maior heterogeneidade na sua distribuição para as famílias, por decil. Observou-se, ainda, que as transferências de programas sociais (TRPS) indicaram um perfil diferente em comparação às transferências ligadas ao trabalho (TLT) em todas as Regiões Metropolitanas analisadas, ou seja, aparecem muito concentrados nos primeiros decis, famílias de renda inferiores, sem 
nenhuma distribuição para as famílias situadas nos últimos decis, indo de encontro aos objetivos desses programas.

\subsection{Impacto Distributivo dos Componentes do Gasto Social}

Este tópico contém a análise do coeficiente de Gini, que indica a concentração na distribuição de renda das famílias.

A Região Metropolitana de Fortaleza (RMF), no quesito renda total, em que se considera o produto da soma da renda própria mais as transferências de renda do governo e da merenda escolar, mostrou uma melhor distribuição nos níveis de renda localizados nos dois extremos, tanto nos inferiores, com as famílias mais pobres, como nos superiores, com as famílias de maior renda.

Tabela 2- Brasil - Impacto distributivo dos componentes do gasto social por decil na Região Metropolitana de Fortaleza (RMF), 2004, (em porcentagem)

\begin{tabular}{lllll}
\hline $\begin{array}{l}\text { Decil de } \\
\text { Renda Própria }\end{array}$ & $\begin{array}{l}\text { Renda } \\
\text { Própria }\end{array}$ & $\begin{array}{l}\text { Renda } \\
\text { Monetária }\end{array}$ & $\begin{array}{l}\text { R.Própria }+ \\
\text { Mer. Escolar }\end{array}$ & Renda Total \\
\hline 1 & 9,95 & 10,27 & 10,40 & 10,69 \\
2 & 9,96 & 10,00 & 9,98 & 10,02 \\
3 & 9,94 & 9,77 & 9,90 & 9,73 \\
4 & 9,97 & 9,77 & 9,91 & 9,72 \\
5 & 9,95 & 9,87 & 9,89 & 9,81 \\
6 & 9,96 & 10,04 & 9,90 & 9,98 \\
7 & 9,94 & 9,86 & 9,88 & 9,81 \\
8 & 9,84 & 9,53 & 9,78 & 9,48 \\
9 & 10,22 & 10,38 & 10,16 & 10,32 \\
10 & 10,26 & 10,52 & 10,20 & 10,46 \\
\hline Total & $\mathbf{1 0 0 , 0 0}$ & $\mathbf{1 0 0 , 0 0}$ & $\mathbf{1 0 0 , 0 0}$ & $\mathbf{1 0 0 , 0 0}$ \\
\hline
\end{tabular}

Fonte: Elaborada pelos autores com base em dados do Instituto Brasileiro de Geografia e Estatística (IBGE), PNAD (2004).

Renda própria: = a remuneração de todas as fontes de renda, exceto: pensões, seguro desemprego e transf. de programas sociais.

Renda monetária $=$ renda própria + transferência de renda das pensões, seguro desemprego e transf. de programas sociais.

Renda total $=$ renda própria + renda monetária + merenda escolar.

Na Região Metropolitana do Recife (RMR), em relação à variável merenda escolar mais a renda própria, constata-se uma concentração maior no primeiro decil e nos dois últimos decis. Entretanto, a distribuição da renda total se dá em maior dimensão nos decis inferiores, o que permite verificar que, na sua totalidade, a renda própria mais as transferências 
de renda do governo possuem um impacto positivo para a população de renda mais baixa, ou seja, aquelas que estão localizadas nos decis mais baixos.

Tabela 3 - Brasil - Impacto distributivo dos componentes do gasto social por decil na Região Metropolitana do Recife (RMR), 2004, (em porcentagem)

\begin{tabular}{lllll}
\hline $\begin{array}{l}\text { Decil de } \\
\text { Renda Própria }\end{array}$ & $\begin{array}{l}\text { Renda } \\
\text { Própria }\end{array}$ & $\begin{array}{l}\text { Renda } \\
\text { Monetária }\end{array}$ & $\begin{array}{l}\text { R.Própria }+ \\
\text { Mer. Escolar }\end{array}$ & Renda Total \\
\hline 1 & 9,96 & 10,33 & 10,32 & 10,67 \\
2 & 9,96 & 10,45 & 9,95 & 10,45 \\
3 & 9,98 & 9,92 & 9,95 & 9,89 \\
4 & 9,94 & 10,04 & 9,90 & 10,00 \\
5 & 9,97 & 9,96 & 9,93 & 9,91 \\
6 & 10,01 & 9,84 & 9,97 & 9,80 \\
7 & 9,90 & 9,71 & 9,85 & 9,67 \\
8 & 9,98 & 9,44 & 9,93 & 9,40 \\
9 & 10,06 & 10,03 & 10,01 & 9,98 \\
10 & 10,24 & 10,28 & 10,19 & 10,24 \\
\hline Total & $\mathbf{1 0 0 , 0 0}$ & $\mathbf{1 0 0 , 0 0}$ & $\mathbf{1 0 0 , 0 0}$ & $\mathbf{1 0 0 , 0 0}$ \\
\hline
\end{tabular}

Fonte: Elaborada pelos autores com base em dados do Instituto Brasileiro de Geografia e Estatística (IBGE), PNAD (2004)

Renda própria: $=$ a remuneração de todas as fontes de renda, exceto: pensões, seguro desemprego e transf. de programas sociais.

Renda monetária $=$ renda própria + transferência de renda das pensões, seguro desemprego e transf. de programas sociais.

Renda total $=$ renda própria + renda monetária + merenda escolar .

Dentre as três regiões metropolitanas nordestinas, no entanto, a Região Metropolitana de Salvador foi a que obteve melhor resposta em relação à introdução dos gastos sociais na renda das famílias.

Tal fato significa que, na referida região metropolitana, os gastos sociais conseguiram melhorar a distribuição de renda e, assim, foi obtido um impacto redistributivo positivo, significando que os gastos sociais foram bem focalizados e eficientes, diferentemente do que aconteceu nas outras regiões metropolitanas nordestinas.

Os dados da Região Metropolitana de Salvador (RMS) indicam que a mesma foi aquela onde o impacto distributivo do gasto social por decil na renda per capita familiar obteve uma melhora positiva. Isso evidencia que a Região analisada configura-se como a que melhor distribuiu os recursos sociais na renda das famílias, embora, na distribuição entre os decis, a região em apreço tenha apresentado uma distribuição mais centrada nos níveis de renda mais baixos de acordo com a Tabela 4. 
Quando passa-se a analisar o coeficiente de Gini antes da introdução dos gastos sociais na renda das famílias, nas Regiões Metropolitanas do Nordeste, observa-se que a Região Metropolitana de Salvador (RMS) apresentou a menor concentração de renda entre as três regiões estudadas do Nordeste (Tabela 5).

Tabela 4 - Brasil - Impacto distributivo dos componentes do gasto social por decil na Região Metropolitana de Salvador (RMS), 2004, (em porcentagem)

\begin{tabular}{lllll}
\hline $\begin{array}{l}\text { Decil de } \\
\text { Renda Própria }\end{array}$ & $\begin{array}{l}\text { Renda } \\
\text { Própria }\end{array}$ & $\begin{array}{l}\text { Renda } \\
\text { Monetária }\end{array}$ & $\begin{array}{l}\text { R. Própria }+ \\
\text { Mer. Escolar }\end{array}$ & Renda Total \\
\hline 1 & 10,00 & 9,30 & 10,33 & 10,51 \\
2 & 10,00 & 9,39 & 10,01 & 10,29 \\
3 & 10,01 & 9,16 & 9,98 & 10,01 \\
4 & 10,00 & 9,07 & 9,96 & 9,90 \\
5 & 9,98 & 9,05 & 9,94 & 9,87 \\
6 & 9,98 & 9,10 & 9,94 & 9,91 \\
7 & 9,96 & 9,05 & 9,91 & 9,89 \\
8 & 10,09 & 17,86 & 10,04 & 9,97 \\
9 & 9,94 & 9,28 & 9,89 & 10,12 \\
10 & 10,04 & 8,74 & 9,99 & 9,5 \\
\hline Total & $\mathbf{1 0 0 , 0 0}$ & $\mathbf{1 0 0 , 0 0}$ & $\mathbf{1 0 0 , 0 0}$ & $\mathbf{1 0 0 , 0 0}$ \\
\hline
\end{tabular}

Fonte: Elaborada pelos autores com base em dados do Instituto Brasileiro de Geografia e Estatística (IBGE), PNAD (2004)

Renda própria: $=$ a remuneração de todas as fontes de renda, exceto: pensões, seguro desemprego e transf. de programas sociais.

Renda monetária $=$ renda própria + transferência de renda das pensões, seguro desemprego e transf. de programas sociais.

Renda total $=$ renda própria + renda monetária + merenda escolar.

Tabela 5 - Brasil - Coeficiente de Gini para análise do impacto distributivo antes e após a introdução dos componentes do gasto social na renda das famílias nas Regiões Metropolitanas selecionadas, 2004.

\begin{tabular}{llll}
\hline Renda Própria & Fortaleza & Recife & Salvador \\
\hline Coeficiente de GINI antes & 0,6319 & 0,6332 & 0,6288 \\
Coeficiente de GINI após & 0,6299 & 0,6291 & 0,6263 \\
\hline
\end{tabular}

Fonte: Elaborada pelos autores com base em dados do Instituto Brasileiro de Geografia e Estatística (IBGE), PNAD (2004).

Renda própria per capita = a remuneração de todas as fontes de renda, exceto: pensões, seguro desemprego e transf. de programas sociais. 
Analisando os dados da tabela 5, e comparando a Região Metropolitana de Fortaleza (RMF) com a Região Metropolitana de Recife (RMR) e Região Metropolitana de Salvador (RMS), nota-se que embora tenha havido uma melhora no coeficiente de Gini nessa região após a introdução dos gastos sociais, a mesma apresentou a pior distribuição no que se refere à renda total, ou seja, a renda é mais concentrada nesta região.

Observa-se que, mesmo após a incidência das transferências sociais, a distribuição de renda medida pelo coeficiente de Gini, demonstrou uma pequena melhora em relação à renda própria, ou seja, os gastos sociais conseguiram diminuir a concentração de renda em todas as regiões estudadas.

As regiões metropolitanas de Salvador e Recife, que compõem a Região Nordeste, conjuntamente com Fortaleza, apresentaram um desempenho melhor quanto à distribuição de renda per capita após a introdução dos gastos sociais 0,6263 e 0,6291, respectivamente, contra 0,6299, da RMF. Em termos globais, a RMR demonstrou o melhor desempenho, isto é, antes da introdução dos recursos dos gastos sociais, o índice de Gini era de 0,6332 e após a introdução de tais gastos o mesmo índice passou para 0,6291. Entretanto, a concentração medida pelo coeficiente de Gini, mesmo que reduzida com a introdução dos gastos sociais ainda permanece estritamente alta.

Logo, ao compararmos as variáveis estudadas como componentes do gasto social, pode-se estabelecer um paralelo importante. As transferências de renda de programas sociais e a merenda escolar ficaram extremamente concentradas nos decis mais baixos, isto é, nas famílias cuja renda per capita familiar atende o objetivo dessas transferências. E pode-se observar, também, que as transferências de renda de programas sociais possuem características mais progressivas na Região Nordeste do que a transferência de renda ligada ao trabalho, o que pode ser em parte explicado pela menor incidência do trabalho formal entre a população de baixa renda, nesta Região.

Esta observação põe em relevo as diferenças regionais e suscita dúvidas sobre a possibilidade de que, através de programas de transferência de renda, o governo consiga tirar essas famílias de renda per capita mais baixa de forma definitiva da realidade atual em que vivem. Nesse sentido, Barros et al. (2007), em seu estudo sobre os determinantes imediatos da queda da desigualdade de renda brasileira, verifica que a associação entre as distribuições da taxa de participação no mercado de trabalho, juntamente com a renda proveniente do trabalho pelos membros adultos da família, não teve grande impacto na queda do grau da desigualdade. Esse resultado deve-se ao fato de que, embora no período do estudo - entre 2001 e 2005 - tenha ocorrido um aumento 
significativo na taxa de ocupação, o mesmo não se traduziu como fator importante para redução da pobreza, indicando que os trabalhadores provenientes das famílias mais pobres não foram contemplados com esses novos postos de trabalho criados. Assim sendo, o autor constata que a renda não derivada de trabalho ${ }^{5}$ foi responsável por $50 \%$ da redução da desigualdade, e que a renda proveniente do trabalho ${ }^{6}$ explica um terço dessa queda, embora este último represente $75 \%$ da composição da renda total familiar. Ou seja, a renda derivada de programas sociais parece importante como elemento redistributivo, o que reforça as indicações destacadas por este trabalho.

\section{Considerações Finais}

Tendo-se como linha geral de análise, neste trabalho, a estratégia governamental para correção de desigualdades sociais decorrentes das externalidades, procurou-se descobrir os impactos dessas ações naquilo que se denomina redistribuição de renda. Para tal utiliza-se como instrumento de análise o coeficiente de Gini, que identifica a concentração na distribuição de renda das famílias, antes e após a introdução dos gastos sociais.

Constata-se que a Região Metropolitana do Recife (RMR) antes da introdução dos gastos sociais era a região com maior concentração de renda e que todas as Regiões Metropolitanas do Nordeste após a introdução dos gastos sociais apresentaram melhora no indicador - coeficiente de Gini - ou seja, os gastos sociais apresentaram impacto positivo no que se refere à diminuição da concentração de renda.

Nessa perspectiva, procurou-se trabalhar com algumas variáveis que efetivamente são destinadas ao atendimento dos mais pobres. Notou-se claramente que as políticas sociais governamentais que se destinam pontualmente às famílias mais pobres (auxílio gás, bolsa escola, bolsa família, PETI, entre outros) têm resultado num impacto muito maior nessas famílias do que nas famílias situadas nos decis acima, que não se constituem população alvo desses programas.

A essência desta estratégia foi identificada nos gastos sociais analisados - pensão, seguro desemprego, transferência de renda de programas sociais e merenda escolar. Dentro desta óptica, ao analisarem-se as variáveis transferências de renda de programas sociais e merenda escolar,

5 Composta pelas transferências governamentais e privadas, e pelos rendimentos dos ativos das famílias.

6 A renda proveniente do trabalho é composta por dois determinantes: i) proporção dos membros da família que se encontra ocupado no mercado de trabalho e, ii) a média da remuneração dos adultos da família ocupados - renda per capita. 
constatou-se que os objetivos por elas definidos deixaram bons resultados no aumento dos rendimentos no universo dos mais pobres, enquanto as variáveis: pensão mais seguro desemprego - TLT - tiveram menos impacto sobre as famílias de renda mais baixa.

É oportuno sugerir que as análises de impactos sociais de gastos do governo, no Brasil, não devem ser feitas olhando sob a óptica do país como um todo. Os resultados aqui encontrados sugerem ser importante levar em conta a dimensão espacial, o que exige a identificação e caracterização da realidade de cada situação onde se deseja intervir.

Dessa forma, o desafio que se coloca para as sociedades contemporâneas é o de articular ações específicas de governo com a iniciativa da esfera privada. Evidentemente, o governo deverá concentrar esforços no sentido de melhorar as condições da pobreza, reduzindo as desigualdades sociais. Contudo, cabe à sociedade civil se somar às políticas sociais governamentais no sentido de ampliar os benefícios elevando o seu bem-estar, com a promoção de programas sociais voltados para a maioria da população carente.

Por fim, vale ressaltar que os resultados obtidos neste trabalho apontam para a necessidade de estudos adicionais para que se possa ter um melhor entendimento dos fatores que interferem no desempenho diferenciado dos programas analisados nas Regiões Metropolitanas do Nordeste. Fez-se aqui uma primeira identificação dos impactos de tais programas, porém as diferenças encontradas indicam ser necessário mais esforço de entendimento das variáveis intervenientes, para que os programas em exame possam vir a ser redefinidos de forma a que os mesmos possam ter impactos mais homogêneos.

\section{Referências}

ALBUQUERQUE, R. C. A. Questão social: balanço de cinco décadas e agenda para o futuro. In: VELLOSO, J. P. R.; ALBUQUERQUE, R. C. (Org.). Cinco décadas de questão social e os grandes desafios do crescimento social. Rio de Janeiro: José Olympio, p. 65146, 2005.

ARRIAGADA, I. Dimensiones de la pobreza y políticas desde una perspectiva de gênero. Revista de La Cepal, n. 85, p. 101-113, abr. 2005.

BARROS, R.; HENRIQUES, R.; MENDONÇA, R. A estabilidade inaceitável:desigualdade e pobreza no Brasil. In: HENRIQUES, R. Desigualdade e pobreza no Brasil. Rio de Janeiro: IPEA, 2000.

BARROS, R. P.; CARVALHO, M. Desafios para a política social brasileira. Texto para Discussão, n. 985. IPEA, 2003.

BARROS, R. P. et al.. Determinantes imediatos da queda de desigualdade de renda brasileira. Texto para Discussão, n. 1253, IPEA, 2007. 
BRAVO, D.; CONTRERAS, D. La distribución del ingreso en Chile 1990-1996: análisis de los efectos del mercado de trabajo y de las políticas sociales. Memórias de la primera fase del foro de equidad social. BID, 2004. Cap 6.

COHN, A. Transferência de renda e questão social. In: VELLOSO, J. P. R. e ALBUQUERQUE, R. C. (Org.). Rio de Janeiro: José Olympio, p. 223-247, 2005. jun./dez. 1995.

Políticas Sociais e Pobreza no Brasil. Planejamento de Políticas Públicas, n. 12,

DIAZ, M. D. M. Desigualdades socioeconômicas na saúde. Revista Brasileira de Economia, Rio de Janeiro, v. 57, n. 1, p. 7-25, jan./mar. 2003.

HENRIQUES, R. (Org.). Desigualdade e pobreza no Brasil. Rio de Janeiro: IPEA, 2000.

HERRÁN, C. A. Reduzindo a pobreza e a desigualdade no Brasil. Brasília: Dupligráfia, 2005.

INSTITUTO BRASILEIRO DE GEOGRAFIA E ESTATÍSTICA. Banco de Dados Agregados. Sistema IBGE de Recuperação Automática - SIDRA. Disponível em: <http://www.sidra. ibge.gov.br>. Acesso em 20 maio 2006.

IRARRÁZAVAL, I. El impacto redistributivo del gasto social: una revisión metodológica de estudios latinoamericanos. Santiago: CEPAL, 1994.

LÖWI, T. J. American business, public policy, case studies and political theory. World Politics, p. 677-725, 1964.

MARICATO, E. Urbanismo na periferia do mundo globalizado: metrópoles brasileiras. 2000. Disponível em: <http://www.scielo.br>. Acesso em 3 ago. 2005.

MARQUES, E. C.; TORRES, H. G. Pobreza e distribuição espacial de grupos sociais na metrópole de São Paulo. Caderno Adenauer, São Paulo, v. 6, n. 1, 2004.

MEDEIROS, M. A trajetória do Welfare State no Brasil: papel redistributivo das políticas sociais dos anos 1930 aos anos 1990. Texto para Discussão n. 852, IPEA, 2001.

. A importância de se conhecer melhor as famílias para a elaboração de políticas sociais na América Latina. Planejamento e Políticas Públicas, n. 22, 2000.

MENDES, M. Federalismo fiscal. In: BIDERMAN, C.; ARVATE, P. (Org.). Economia do setor público no Brasil. Rio de Janeiro: Elsevier, 2005. p. 421-461.

MOSTAJO, R. Gasto social y distribución del ingreso: caracterización e impacto redistributivo en países seleccionados de América Latina y El Caribe. Série Reformas Econômicas, n. 69, p. 58, mayo 2000.

RAMOS, L.; VIEIRA, M. L. Desigualdade de rendimentos no Brasil nas décadas de 80 e 90: evolução e principais determinantes. Texto para Discussão n. 803, IPEA, 2001.

REZENDE, F. et al.. Contribuintes e cidadãos compreendendo o orçamento federal. Rio de Janeiro: FVG, 2002.

ROCHA, S. Pobreza no Brasil: o que mudou nos últimos 30 anos? In: VELLOSO, J. P. R.; ALBUQUERQUE, R; C. (Org.). Cinco décadas de questão social e os grandes desafios do crescimento social. Rio de Janeiro: José Olympio, p. 181-219, 2005.

. Pobreza no Brasil: afinal, de que se trata? Rio de Janeiro: FGV, 2005.

SILVA, M. O. S. et al.. A Política social brasileira no século XXI. A prevalência dos programas de transferência de renda. São Paulo: Cortez, 2004. 
SIQUEIRA, M. L.; RAMOS, F. S. Incidência tributária. In: BIDERMAN, C.; ARVATE, P. (Org.). Rio de Janeiro: Elsevier, p. 155-172, 2005.

SIQUEIRA, R. B. et al.. Teoria da tributação ótima. In: BIDERMAN, C.; ARVATE, P. (Org.). Rio de Janeiro: Elsevier, p. 173-187, 2005.

SOARES, M. C. A mensuração do impacto redistributivo dos gastos sociais: um estudo para a região metropolitana de São Paulo. Texto para Discussão n. 643, IPEA, 1999.

. Impacto distributivo do gasto social: uma análise a partir da PCV/1998. Texto para Discussão n. 732, IPEA, 2000.

TORRES, H. G.; MARQUES, E. Políticas sociais e território: uma abordagem metropolitana. Revista São Paulo em Perspectiva. São Paulo: Fundação Seade, 2004.

. Reflexões sobre a hiperperiferia: novas e velhas faces da pobreza no entorno metropolitano. Revista Brasileira de Estudos Urbanos e Regionais, São Paulo, n. 4, p. 49-70, 2001.

VÉLEZ, C. E. Eficiencia, equidad y reestructuración sectorial del gasto público social. Texto n. 80, Estudos Económicos del Banco de la República, Colombia, 1997.

A quien beneficia el gasto público social? Revista del Banco de la República. Disponível em: < http://www.lablaa.org/blaavirtual/letra-r/revista/nitsept.htm > . Acesso em 16 jul. 2005. 
Apêndice

Tabela A.1 - População e variação relativa das famílias na linha de pobreza nas regiões metropolitanas do nordeste do Brasil, entre 2001 e 2004

\begin{tabular}{|c|c|c|c|c|c|c|c|}
\hline Regiões & População & População & Famílias & Famílias & $\%$ & $\%$ & $\Delta \%$ \\
\hline Metropolitanas & 2001 & 2004 & $\begin{array}{l}\text { linha de } \\
\text { pobreza } \\
2001\end{array}$ & $\begin{array}{l}\text { linha de } \\
\text { pobreza } \\
2004\end{array}$ & $\begin{array}{l}\text { Famílias } \\
\text { pobres } \\
2001\end{array}$ & $\begin{array}{l}\text { Famílias } \\
\text { pobres } \\
2004\end{array}$ & $\begin{array}{l}2001 / \\
2004\end{array}$ \\
\hline Fortaleza-CE & 3.064 .271 & 3.295 .915 & 236.113 & 253.178 & 7,70 & 7,68 & 7,23 \\
\hline Recife-PE & 3.394 .588 & 3.560 .552 & 267.571 & 287.300 & 7,90 & 8,06 & 7,37 \\
\hline Salvador-BA & 3.093 .260 & 3.298 .592 & 226.226 & 214.398 & 7,31 & 6,50 & $-5,23$ \\
\hline Brasil & 169.369 .557 & 182.060 .108 & 11.210 .603 & 11.105 .744 & 6,62 & 6,10 & $-0,99$ \\
\hline
\end{tabular}

Fonte: Elaborada pelos autores com base em Instituto Brasileiro de Geografia e Estatística (2006).

Tabela A.2 Brasil - Distribuição do gasto social por decil de renda na Região Metropolitana do Recife (RMR), 2004, (em porcentagem)

\begin{tabular}{llllll}
\hline $\begin{array}{l}\text { Decil de } \\
\text { Renda Própria }\end{array}$ & TLT & TRPS & $\begin{array}{l}\text { Transferências } \\
\text { de Renda }\end{array}$ & $\begin{array}{l}\text { Merenda } \\
\text { Escolar }\end{array}$ & $\begin{array}{l}\text { Gasto } \\
\text { Social }\end{array}$ \\
\hline 1 & 8,62 & 47,35 & 14,56 & 87,09 & 18,23 \\
2 & 12,13 & 37,62 & 16,04 & 9,60 & 15,71 \\
3 & 9,75 & 6,17 & 9,20 & 2,24 & 8,85 \\
4 & 12,04 & 6,41 & 11,18 & 0,86 & 10,66 \\
5 & 11,44 & 0,51 & 9,76 & 0,13 & 9,27 \\
6 & 9,01 & 1,61 & 7,88 & 0,09 & 7,48 \\
7 & 8,89 & 0,32 & 7,58 & 0,00 & 7,19 \\
8 & 4,04 & 0,00 & 3,42 & 0,00 & 3,24 \\
9 & 11,40 & 0,00 & 9,65 & 0,00 & 9,16 \\
10 & 12,69 & 0,00 & 10,75 & 0,00 & 10,20 \\
Total & $\mathbf{1 0 0 , 0 0}$ & $\mathbf{1 0 0 , 0 0}$ & $\mathbf{1 0 0 , 0 0}$ & $\mathbf{1 0 0 , 0 0}$ & $\mathbf{1 0 0 , 0 0}$ \\
\% Renda Própria & $\mathbf{7 , 5 4}$ & $\mathbf{1 , 3 7}$ & $\mathbf{8 , 9 1}$ & $\mathbf{0 , 4 8}$ & $\mathbf{9 , 3 8}$ \\
\hline
\end{tabular}

Fonte: Elaborada pelos autores com base em Instituto Brasileiro de Geografia e Estatística (IBGE) e PNAD (2004).

TLT $=$ pensão + seguro desemprego.

TRPS $=$ transferência de renda de programas sociais.

Transferências de Renda $=$ TLT + TRPS e Gastos Sociais $=$ TLT + TRPS + Merenda Escolar. 
Tabela A.3 - Brasil - Distribuição do gasto social por decil de renda na Região Metropolitana de Fortaleza (RMF), 2004, (em porcentagem)

\begin{tabular}{llllll}
\hline $\begin{array}{l}\text { Decil de } \\
\text { Renda Própria }\end{array}$ & TLT & TRPS & $\begin{array}{l}\text { Transferências } \\
\text { de Renda }\end{array}$ & $\begin{array}{l}\text { Merenda } \\
\text { Escolar }\end{array}$ & $\begin{array}{l}\text { Gasto } \\
\text { Social }\end{array}$ \\
\hline 1 & 6,63 & 62,75 & 14,33 & 82,13 & 19,32 \\
2 & 8,49 & 23,18 & 10,51 & 13,09 & 10,70 \\
3 & 7,81 & 5,69 & 7,52 & 2,85 & 7,17 \\
4 & 7,56 & 5,20 & 7,24 & 1,16 & 6,79 \\
5 & 9,89 & 1,59 & 8,75 & 0,40 & 8,14 \\
6 & 12,58 & 1,60 & 11,07 & 0,24 & 10,28 \\
7 & 10,32 & 0,00 & 8,91 & 0,04 & 8,25 \\
8 & 6,51 & 0,00 & 5,61 & 0,04 & 5,20 \\
9 & 14,24 & 0,00 & 12,29 & 0,00 & 11,38 \\
10 & 15,97 & 0,00 & 13,78 & 0,04 & 12,77 \\
Total & $\mathbf{1 0 0 , 0 0}$ & $\mathbf{1 0 0 , 0 0}$ & $\mathbf{1 0 0 , 0 0}$ & $\mathbf{1 0 0 , 0 0}$ & $\mathbf{1 0 0 , 0 0}$ \\
\% Renda Própria & $\mathbf{6 , 8 8}$ & $\mathbf{1 , 1 0}$ & $\mathbf{7 , 9 8}$ & $\mathbf{0 , 6 3}$ & $\mathbf{8 , 6 1}$ \\
\hline
\end{tabular}

Fonte: Elaborada pelos autores com base em Instituto Brasileiro de Geografia e Estatística (IBGE) e PNAD (2004).

TLT $=$ pensão + seguro desemprego.

TRPS = transferência de renda de programas sociais.

Transferências de Renda $=$ TLT + TRPS e Gastos Sociais $=$ TLT + TRPS + Merenda Escolar. 
Tabela A.4 - Brasil - Distribuição do gasto social por decil de renda na Região Metropolitana de Salvador (RMS), 2004, (em porcentagem)

\begin{tabular}{llllll}
\hline $\begin{array}{l}\text { Decil de } \\
\text { Renda Própria }\end{array}$ & TLT & TRPS & $\begin{array}{l}\text { Transferências } \\
\text { de Renda }\end{array}$ & $\begin{array}{l}\text { Merenda } \\
\text { Escolar }\end{array}$ & $\begin{array}{l}\text { Gasto } \\
\text { Social }\end{array}$ \\
\hline 1 & 7,91 & 65,39 & 13,61 & 80,69 & 18,81 \\
2 & 14,31 & 24,10 & 15,34 & 13,18 & 15,17 \\
3 & 11,17 & 5,06 & 10,50 & 3,71 & 9,97 \\
4 & 9,55 & 3,05 & 8,91 & 1,44 & 8,33 \\
5 & 9,51 & 0,84 & 8,65 & 0,46 & 8,02 \\
6 & 10,49 & 0,28 & 9,70 & 0,32 & 8,97 \\
7 & 10,34 & 1,28 & 9,20 & 0,09 & 8,49 \\
8 & 9,55 & 0,00 & 8,61 & 0,05 & 7,94 \\
9 & 15,65 & 0,00 & 14,10 & 0,00 & 13,00 \\
10 & 1,53 & 0,00 & 1,40 & 0,05 & 1,30 \\
Total & $\mathbf{1 0 0 , 0 0}$ & $\mathbf{1 0 0 , 0 0}$ & $\mathbf{1 0 0 , 0 0}$ & $\mathbf{1 0 0 , 0 0}$ & $\mathbf{1 0 0 , 0 0}$ \\
\% Renda & $\mathbf{5 , 0 5}$ & $\mathbf{0 , 5 6}$ & $\mathbf{5 , 6 1}$ & $\mathbf{0 , 4 7}$ & $\mathbf{6 , 0 8}$ \\
Própria & & & & & \\
\hline
\end{tabular}

Fonte: Elaborada pelos autores com base em Instituto Brasileiro de Geografia e Estatística (IBGE) e PNAD (2004).

TLT $=$ pensão + seguro desemprego.

TRPS $=$ transferência de renda de programas sociais.

Transferências de Renda $=$ TLT + TRPS e Gastos Sociais $=$ TLT + TRPS + Merenda Escolar.

Recebido: 27/02/2009.

Aceito: 15/09/2009. 